\title{
O RECONHECIMENTO EX OFFICIO DO CARÁtER ABUSIVO dA CLÁUSULA DE ELEIÇÃO DE FORO
}

Antonio Carlos Marcato!

SUMARIO: 1. Introduça - 2. Competencia absoluta e relativa - 3. Incompetencia relativa e dedaraço de offio - 4. Caráter abusivo de clausula de eleiça de foro- 5 . A guisa de contusăo - 6. Bibliografia

RESUMO: O reconhecimento ex officio do caráter abusivo da clausula de eleiça de foro tem suscitado, com freqüencia a interposição de agravos. $O$ enfrentamento do tema impóe o prévio exame das questöes envolvendo a competencia (ou a ausencia dela) do órgäo jurisducional perante o qual foi ajuizada açăo

PALAVRAS-CHAVE: Competencia - Reconhecimento Ex Officio Cláusula abusiva - Eleição de foro

ABSTRACT: The recognizing ex officio of the abusive character of the election court clause, has bring out with frequency the usage of appeals. The struggling with the theme demands a previous examination of the matters involving competence (or its absence) of the jurisdictional organ, before which the action was proposed.

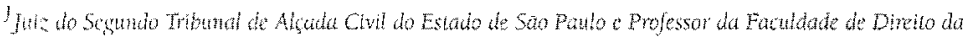
Universidite de suo Pento
} 


\section{INTRODUÇÃO}

São freqüentes os agravos interpostos contra decisões que, pautadas no reconhecimento do caráter abusivo da cláusula eletiva de foro inserta em contratos de adesäo, contêm a proclamação ex officio da incompetência absoluta do juízo, com a determinaçăo de remessa dos autos do processo ao foro do domicilio do réu. E quase que invariavelmente os agravantes sustentam a validade da cláusula em questão, bem como a relatividade da eventual incompetência, passivel de proclamação judicial, portanto, somente se e quando oposta pelo réu a adequada exceçăo nitual declinatória.

\section{COMPETÊNCIA ABSOLUTA E RELATIVA}

O correto enfrentamento do tema ora debatido impöe, sem dúvida alguma, o prévio exame das questöes envolvendo a competência (ou a ausência dela) do órgảo jurisdicional perante o qual foi ajuizada a ação.

Muito embora a doutrina e a jurisprudência já tenham consagrado as expressões competência absoluta e competencia relativa, cremos ser mais adequado o exame das questóes envolvendo o caráter absoluto ou relativo do instituto em foco sob seu aspecto negativo (incompetencia), pois importam apenas as consequências que advêm da incompetência absoluta e relativa, nenhuma utilidade se extraindo da graduação da competência (ou seja, o exame do fenómeno sob o ponto de vista da sua existência).

A higidez dos atos decisórios praticados no processo depende apenas da competência (situação positiva) do órgão jurisdicional perante o qual aquele tramite, irrelevante a sua qualificação, pois em nada aproveita a aferição do grau da competência por ele ostentada; interessa, isto sim, o grau de sua eventual incompetència (situaçăo negativa), pois diferentes as conseqüèncias dervadas de seu caráter absoluto ou relativo, como diferentes são os meios de argüição e reconhecimento de uma ou outra.

Sendo o órgão jurisdicional absolutamente incompetente, é totalmente ilegítimo o processamento da ação perante ele, padecendo de nulidade insanâvel, por decorrência, os atos decisórios proferidos pelo juiz (CPC, arts. $\left.113, \S 2^{\circ}, 122,485,11\right)$, e essa situação de ilegitimidade é infensa 
a correção ou convalidação, daí representar direito da parte - e dever do juiz - a argüição e o reconhecimento (inclusive de ofício), a qualquer tempo e grau, da incompetência absoluta (arts. 113 e 301, II e § 4\%).

A relatividade da incompetência, por sua vez, não acarreta a invalidade de qualquer ato decisório, seja porque em princípio inexistirá ato judicial dessa natureza antes do momento adequado para a dedução da exceção correspondente (ressalvada eventual decisão inaudita altera parte, passível de confirmação ou revogação, no futuro, pelo juiz que atue no órgão ao final reconhecido como competente), seja porque, mantendo-se a parte inerte, isto é, não argüindo o defeito da incompetência na oportunidade e na forma previstas em lei (CPC, arts. 112 e 304 e segs.), tal possibilidade ficará acobertada pela preclusão temporal, com a conseqüente prorrogação (art. 114).

Entencicla a competência como o limite, imposto ao juiz, para o exercício legítimo do poder jurisdicional em processo que tramite no órgão jurisdicional em que atue, a incompetência significa, contrario sensu, justamente a ausência dessa legitimidade, anotando-se, ademais, que a intensidade maior ou menor desse defeito está diretamente relacionada à norma legal ofendida com o ajuizamento da demanda perante órgão incompetente. Por outras palavras, as normas reguladoras da competência encontram sua razão de ser ora no interesse público (v.g., distribuição dos feitos, fundada em critérios objetivos ou funcionais, aos juízos da mesma comarca), ora no interesse da parte (v.g., quando concede vantagem ao credor de alimentos - CPC, art. 100, II), advindo, dessa duplicidade de interesses, conseqüências totalmente diversas.

Prevalecendo para a determinação da competência um critério fundado em norma protetiva de interesse público, a sua inobservância acarretará a absoluta incompetência do órgão jurisdicional perante o qual a demanda loi ajuizada, situação essa imodificável tanto pela vontade do juiz, quanto pela das partes. Sendo prevalente, ao reverso, um critério previsto em norma protetiva do interesse de qualquer das partes, sua vulneração gerará a incompetência relativa do órgão processante, se bem que nesse caso tal incompetência poderá ser afastada tanto por ato da parte (eleição de foro, 
não oposição de exceção declinatónia), quanto por força da lei (v.g., CPC, art. 105).

Tratando-se de incompetência absoluta, os atos decisórios serão nulos, podendo essa nulidade ser reconhecida, como dito, a qualquer tempo e grau de jurisclição, reconhecimento esse não obstado sequer pela superveniéncia de coisa julgada material (CPC, art. 485, II); cuidando-se, porém, de incompetência relativa, o problema será solucionado no curso do processo, quer pela sua proclamaça em julgamento de exceção declinatória, com a consequente remessa dos autos ao ógão competente, quer pela preclusäo derivada da não oposição oportuna da exceção ritual adequada, gerando o fenómeno da prorrogação.

A natureza da incompetencia absoluta afasta a possibilidade de prorrogaçăo, podendo ela - objeçao processual que é -, ser alegada a qualquer tempo e grau de jurisdição e inclusive reconhecida de oficio pelo juiz (CPC, arts. 113 e 301 , II e $84^{\circ}$ ).

Em sintese, a incompetencia absoluta pode (deve, na verdade) ser proclamada de ofício, ao passo que o reconhecimento judicial da relativa sempre depende da argüiça, pela parte prejudicada, de excecăo declinatória, sob pena de prorrogação.

Convèm esclarecer, a esta altura, que essa última assertiva de modo algum encontra aceitação pacifica em sedes doutrinária e jurisprudencial, conforme se demonstra a seguir.

\section{INCOMPETENNCIA RELATIVA E DECLARAÇÃO DE OFICIO}

A

dotanclo tese exposta por LOPES DA COSTA, MONIZ DE ARAGAO sustenta enlaticamente a possibilidacle de o juiz declinar de oficio sua incompetência relativa, afrmando que "No Brasil, lei alguma probe aos juzes dedarar de oficio a incompetencia relativa; tampouco os compele a aceitar passivamente a prorrogaçáo da competencia, por ser relativa. O que nŏo se thes consente de dexar de faze-lo no primeiro momento em que aluem no caso, ao apreciar a petiço inicial, pois ai se firmatá a prorrogaça, que ficará a critério do 
réu obstar." E mais adiante assevera: "Ajuizada ação com infringência de norma de competência territorial, poderá o juiz, no primeiro ato a praticar, que é a apreciaça da petiça inicial, recusar de oficio a competência, como ficou visto no $n^{\circ} 192$, pois, do contrário, preduir-lhe-a a faculdade e a regra da competencia, que nesse preciso momento comportaria o tratamento dispensado à nulidade relativa, passará a subordinat-se unicamente aos principios que regem a anulabilidade, ou seja, apenas o réu poderá impugnar a infração ocorrida, desde que o faça na forma e no prazo dos arts. 297 e 304, sob pena de perder a faculdade de fazê-10, completando-se a prorrogação: a anulabilidade desaparece e o vicio está sanado pela ausência da condição resolutiva."2

Essa posição, também aceita por outros juristas de porte 3 , adquiriu um certo prestígio nos tribunais paulistas, por influência direta dos julgados que emanavarn, até recentemente, da Cảmara Especial do Tribunal de Justiça, à qual compete julgar, enquanto derivadas de incidentes autônomos, todas as questóes envolvendo competência.

Conlorme orientaça dessa Câmara ${ }^{4}$, poderia o juiz reconhecer de ofício a incompetência relativa, desde que não houvesse ainda praticado ato que o vinculasse ao processo; cessaria tal faculdade, no entanto, se já operada a prorrogação da competência por força do artigo 114 - até porque, a essa altura, o juiz estaria vinculado ao processo ${ }^{5}$.

A corrente contrária, que conta com adeptos do porte de BARBOSA

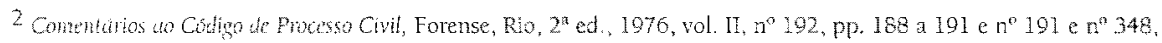
pp. 331 a 334.

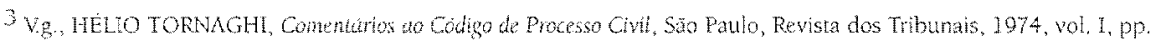
300 C MENDONCA LMA, A now sitematca das excecoses, Revista de Processo, vol. 2, pp. 61 a 76 , entre outros.

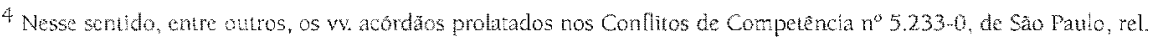
Des. CESAR DE MORAES, julg. 17.1085, n 6.7460, de Cubatan, rel. Des. DiNTO GARCIA, julg. 14.05 .87 e n" 6819-0, de Amaxauba, rel. Des ANICETO ALIENDE, jug 28.05.87 - O E. Prmeiro Tribunal de Alçda Civil de Să Thulo chegou a encampar tat entendimento em sta Sumula 28, com o seguinte enunciado: Pode o Jui deciarar be

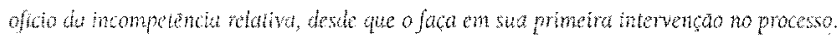

${ }^{5}$ Nunca e demais lembrar cue essa orientacto foi dilada, originalmente. muito mais pela necessidade de lorçar-se o

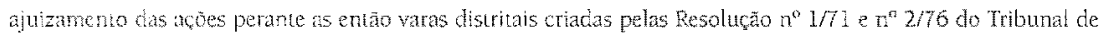
Justęn (naz medida em que alguns advogatos insistiam em promovelas perante os juizos centrais, contando com a prorrogata da competencia e assim oponco indevida resistência ao efetivo funcionamento daquetes juizos), do cue por motivos de ordem téciico processual. 
MOREIRAs e CANDIDO DINAMARCO, sustenta que a lei não confere ao juiz o poder discricionário de reconhecer a incompetencia relativa, face ao contido no artigo 114 do Código, aplicável à luz do artigo 112. E isto porque as regras de determinação da competência relativa atendem precipuamente ao interesse das partes, não sujeito à discricionariedade da autoridade judiciária, sendo ainda certo, à luz dessa premissa, que à parte cabe com exclusividade a faculdade de excepcionar a incompetência relativa, até mesmo porque o ajuizamento da ação no foro ou no juizo relativamente incompetentes poderá redundar em uma situação de vantagem para qualquer dos sujeitos parciais da relaçäo processual.

Nem vale, por outro lado, o argumento de que só caberia tal reconhecimento em se tratando da hipotese do artigo 114, visto que a lei não traça qualquer distinção, nesse particular, ao cuidar das duas causas de prorrogação voluntária da competencia, devendo ser desprezados, finalmente, argumentos de caráter pragmático, pois em "um regime de direito escrito, de legalidade processual estrita, não se pode deixar ao magistrado a faculdade de aceitar ou näo o processo segundo a sua própria comodidade".s

Necessärio observar, a esta altura, que essa última corrente é hoje absolutamente prevalente em sede jurisprudencial, a ponto de o Colendo Superior Tribunal de Justiça haver editado, a seu respeito, a Súmula 33, dispondo que "A incompetência relativa não pode ser declarada de oficio".

Concluindo e reiterando: o juiz deve declinar de ofício a incompetência absoluta, até porque esse defeito contamina irremediavelmente o processo, acarretando sua nulidade absoluta, que só não mais poderá ser judicialmente reconhecida após o decurso do biênio fixado para a propositura da ação rescisória (CPC, art. 485, II). A incompetência relativa, por seu tumo, resulta apenas da afronta, por ocasião do ajuizamento da ação, de critério legal protetivo do interesse da parte, podendo, por isso mesmo, ser arguida pelo prejudicado, caso queira, no prazo e na forma

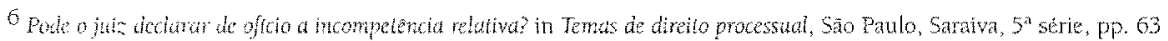
a 76 .

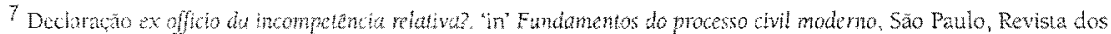

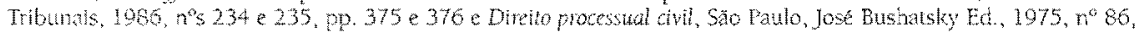
pp. $138 \mathrm{e} 139$.

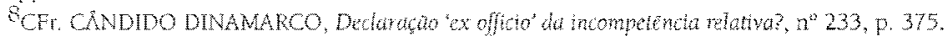


previstos em lei; não o lazendo, opera-se a preclusão e, por consequência, a prorrogaçăo da competência, como previsto no artigo 114 do Código de Processo Civil.

Partindo da correta conclusão de que ao juiz é defeso reconhecer de ofício a incompetência relativa, é lícito também concluir-se, à luz da dogmática processual, que a invalidade da cláusula eletiva de foro só pode ser judicialmente proclamada, ainda que incidentalmente, se e quando a parte prejudicada aponta o defeito em sua resposta.

Reconhecida que seja a invalidade, com o conseqüente afastamento do critério contratual determinativo da competência territorial, prevalecerá aquele contemplado no artigo 94 do Código do Código de Processo Civil, ensejando a pronta remessa dos autos do processo ao foro do domicílio do réu.

Convém lembrar, todavia, que a validade da correspondente decisão judicial estará condicionada à relatividade da incompetência do órgão jurisdicional; sendo ela absoluta, este grau máximo de incompetencia derivaria, necessariamente, do prévio reconhecimento da nulidade da cláusula, que não permitiria proclamação de ofício, sob pena de ficar patenteada, por sua vez, a nulidade da própria decisão, contaminada que estaria pelo vicio da incompetência.

Acrescente-se ainda, em relorço à linha de argumentação até aqui desenvolvida, que o reconhecimento da invalidade da cláusula eletiva näo acarretaria, por si só - e não obstante a sua influência imediata e direta no destino do processo -, a transmutação da incompetência relativa em absoluta, nem afetaria a higidez daquele, impondo-lhe, apenas e tăo-so, o deslocamento para outro orgão jurisdicional, qual seja o competente.

\section{CARATER ABUSIVO DA CLAUSULA DE ELEICÃO DE FORO}

\section{$D$} iante das dificuldades até aqui expostas, tudo indica que o problema ora enfocado deva ser solucionado sob outras luzes.

Dúvida não há de que a cláusula eletiva de foro, estabelecida em contrato de adesão pela parte economicamente mais forte, poderá revelar-se 
abusiva se e quando impuser, ao contratante mais fraco, sérios (e por vezes insuperáveis) óbices ao pleno acesso à jurisdição e à sua defesa no processo, assim afrontando as correspondentes garantias constitucionais; e essa alronta, abstraidos outros aspectos processuais (de menor ou nenhuma importancia em confronto com ditas garantias), seria suficiente, por si só, para justificar a pronta remessa dos autos ao foro do domiclio da parte hipo suficiente. Melhor dizendo, a observância da técnica processual visa a atender, precipuamente, aos designios constitucionais e não, à evidência, impor onus e gravames indevidos a um dos sujeitos processuais; e deve a autoridade judiciária, diante de situaçóes que possam, efetiva ou potencialmente, colocar em risco tais designios, adotar de imediato as medidas corretivas adequadas, atenta ao dever de permanente vigilância $e$ delesa dos ditames constitucionais, imposto a todos os cidadãos e, em especial, aos integrantes do Poder Judiciário.

\section{5. À GUISA DE CONCLUSÃO}

$E$ imperativo, no entanto, que o julgador näo se deixe levar pela tentação de considerar toda e qualquer cláusula eletiva de foro sempre abusiva e ilegal; antes, deve ter em mente que o reconhecimento e a proclamação da afronta a preceitos constitucionais demandam o exame, caso a caso, das circunstâncias que envolvem o contrato contendo a cláusula em questão, não sendo lícita, nem juridica, a pura e simples generalização.

No regime do Código de Defesa do Consumidor (ao qual se submetem, por certo, os litigios e os processos envolvendo contratos de consórcio e de empréstimos e financiamentos bancários, entre tantos outros), as mencionadas garantias constitucionais ganham ainda maior vulto e relevo, merce da generosa e inescondível intenção da lei em proteger, nos intrincados e complexos negócios dos cias correntes, aquele contratante que, por razóes pessoais e/ou económicas, se encontre em situaça de desvantagem perante o outro. E essa intenção se revela em sua plenitude quando a lei reconhece como abusiva - e comina de inválida - a cláusula contratual que viole o direito básico, garantido ao consumidor, de facilitaçào de sua delesa (arts. 6\%, VIII e 51, NV e XV, conjugados). 
Ao eleger o foro onde está localizada sua sede, em cláusula adrede preparada, como sendo o competente para as açóes derivadas do descumprimento do contrato, determinadas empresas e instituiçôes (que não raramente possuem agências e representantes em praticamente todo o território nacional) indevidamente impōem ao outro contratante, mormente quando domiciliado em outro Estado, sérias dificuldades ao pleno exercício de seu direito de defesa, representadas, à guisa de exemplos, por aquelas relacionadas ao custo do processo, à contratação de patrono e ao deslocamento à comarca eleita.

Esses óbices, ainda que eventualmente impostos de modo não intencional, autorizam e justificam a determínação de remessa dos autos do processo ao foro do domicilio do réu; e isto porque a questăo em debate envolve, à evidência, tema muito mais sério e grave que a simples possibilidade de ser reconhecida de ofício a nulidade de cláusula abusiva ou a incompetência relativa ou, ainda, de se tratar de incompetência absoluta: cuida-se, em verdade, da necessidade (e não simples faculdade) de atendimento das exigências do devido processo legal, mister do qual todos os integrantes do Poder Judiciário devem, permanente e intransigentemente, se desincumbir.

\section{REFERENCIAS BIBLIOGRAFICAS}

ALVES, Barbosa Moreira. Pode o Juiz declarar de oficio a incompetencia relativa? "in" Temas de Direito Processual, Sa Paulo: Saraiva, 5 Série $5 / A$.

DNAMARCO, Candido Rangel. Declaraça "Ex Offico" da incompetência relativa? "in" Fundamentos de processo cwil modemo, sao Paulo: Revista dos Tribunais, 1986, n²34 e 236

LIMA, Mendonça A nova sistemática das exceçóes. Revista de Processo, wol 2.

MONZZ DE ARAGÄO, Egas. Cometários ao Código de Processo Civil, Rlo de Janieor: Forense. $2^{2}$ ed. 1976 , vol If. TORNAGHi, Hẹlio. Comentanos no Código de Processo Civil, São Paulo: Revista dos Tribunais, 1974 